\title{
Lentinus squarrosulus Mont. Mushroom: Molecular Identification, In vitro Anti-Diabetic, Anti-Obesity, and Cytotoxicity Assessment
}

\author{
(1) Oyindamola Olajumoke ABIODUN 1 ,4* (1) Adenike Martha ALEGE1, (1) Precious Ulonnam EZURIKE², (1) Abraham NKUMAH ${ }^{3}$, \\ (1) Oluwatosin ADELOWO1, (1) Tolulope Aderinola OKE ${ }^{4}$ \\ 1 University of Ibadan, Faculty of Basic Medical Sciences, Department of Pharmacology and Therapeutics, Ibadan, Nigeria \\ 2Michael Okpara University of Agriculture, College of Natural Sciences, Department of Biochemistry, Umudike, Nigeria \\ 3University of Ibadan, Faculty of Pharmacy, Department of Pharmacognosy, Ibadan, Nigeria \\ «University of Ibadan, Faculty of Pharmacy, Department of Pharmacology and Toxicology, Ibadan, Nigeria
}

\begin{abstract}
Objectives: Mushrooms are fungi with nutritional and health benefits. Lentinus squarrosulus Mont., an edible fungus, has traditional usage and relevance in local therapy for managing metabolic diseases. In that view, this study aimed to evaluate the in vitro anti-obesity, anti-diabetic, and cytotoxic potential of the chloroform/methanol extract (CME) and aqueous extract (AE) of the mushroom.

Materials and Methods: L. squarrosulus was identified using molecular biology tools. The CME and AE were obtained sequentially and, then, subjected to $\alpha$-amylase, $\alpha$-glucosidase, and lipase inhibitory enzyme assays as well as total phenolic content (TPC) and flavonoid content (TFC) estimations. The cytotoxic potential of extract fractions of $L$. squarrosulus was assessed using the brine shrimp lethality assay.

Results: The molecular identification of the mushroom displayed that the internal transcribed spacer sequence was an equivalent match to that of $L$. squarrosulus with a high percentage similarity, and thus assigned a unique accession number (KT120043.1). The CME of L. squarrosulus had higher TPC, TFC, and $\alpha$-glucosidase inhibitory activity than AE. Furthermore, AE of the mushroom showed a higher lipase inhibitory potential with an IC ${ }_{50}$ value of $22.28 \pm 0.65 \mu \mathrm{g} / \mathrm{mL}$ than the CME, while that of the reference, i.e. orlistat was $2.28 \pm 0.34 \mu \mathrm{g} / \mathrm{mL}$. However, these extracts exhibited very low or no $\alpha$-amylase inhibitory and cytotoxic activity at the tested concentrations.
\end{abstract}

Conclusion: This study reveals that CME of L. squarrosulus, rich in polyphenols and flavonoids, possesses considerable $\alpha$-glucosidase and lipase inhibitory activities.

Key words: Lentinus squarrosulus, lipase, $\alpha$-Glucosidase, $\alpha$-Amylase, cytotoxicity

\section{INTRODUCTION}

Diabetes mellitus (DM) is a health disease that results from an impairment in the secretion of insulin and some unavoidable degree of resistance to insulin in the periphery, leading to constant hyperglycemia. The chronic form of this hyperglycemia can disrupt protein, lipid, and carbohydrate metabolism leading to serious health concerns. Affecting about $90 \%$ of diabetics globally is the type-2 form of the disease (T2DM), making it the most common.' A steady rise in cases and diabetes prevalence has been recorded over the past few decades. More than 422 million people are diabetic around the world, and diabetes causes the deaths of about 1.6 million people every year. ${ }^{2} \alpha$-Amylase and $\alpha$-glucosidase are sugar-hydrolyzing complex enzymes that are mainly secreted from the pancreas and the intestinal chorionic epithelium, respectively. Inhibiting these enzymes is an approach for T2DM therapy as well as reducing postprandial glucose levels, since it can prevent excess glucose absorption by decreasing the rate of carbohydrate breakdown. ${ }^{3}$ This metabolic disease also has a close relationship with obesity. ${ }^{4}$ Obesity is defined as an abnormal or excessive accumulation of 
massive body storage fats, which may be caused by a mismatch between the rate of intake and expenditure of energy. ${ }^{5}$ The number of obesity and overweight cases is increasing and if these trends continue, it is estimated that 2.7 billion adults will be overweight, over 1 billion people will be affected by obesity, and 177 million adults will severely be affected by obesity by $2025 .^{2}$ Furthermore, an increase in the storage of lipids in the pancreas can instigate the abnormal functioning of the insulin-producing pancreatic $\beta$-cells, which may result in T2DM. ${ }^{6}$ The major enzyme in lipid digestion is pancreatic lipase. Its role is to facilitate the absorption of dietary fats by catalyzing the hydrolysis of triacylglycerol into free fatty acids and monoacylglycerol in the lumen of the intestine. ${ }^{7}$ Research interest on inhibitors of pancreatic lipase activity has received much attention, possibly due to their anti-obesity activity by delaying the lipid breakdown process. ${ }^{8}$

Mushrooms are widespread. They are fungi visible with definitive basidiocarps (fruiting bodies). Edible mushrooms have served as food supplements and source of bioceuticals because they possess a myriad of compounds that elicit biological activities and play vital roles in human nutrition and health. Lentinus squarrosulus mushroom has been reported to be commonly eaten with medicinal properties. L. squarrosulus is edible and belongs to the Polyporaceae family. The fruiting body, known as the basidiocarp, is morphologically characterized by a whitish-greyish surface with conspicuous squamules. ${ }^{9}$ L. squarrosulus usually exists in old or fallen tree trunks, and buried or exposed roots of decaying deciduous trees in some tropical rain forest regions of Africa (Nigeria) and Asia. It usually grows in cespitose clusters of up to three to six basidiocarps. ${ }^{10}$ In Nigeria, L. squarrosulus is popularly known as "Ero atakata" in South-Eastern part", and "Olu-awo, erirokiro, or osun two" in South-Western part. ${ }^{12}$ In traditional medicine, it is used in ulcer treatments, ${ }^{13}$ alleviate anemic symptoms, decrease the chances of infertility in both men and women ${ }^{14}$, and lower the risk of metabolic diseases. ${ }^{15,16}$ Previous studies have indicated that $L$. squarrosulus contains phenolics, tannins, saponins, flavonoids, alkaloids, terpenes, quinolones, and anthraquinones. ${ }^{17}$ It has also been reported to possess antimicrobial, ${ }^{18}$ immunomodulatory, ${ }^{19}$ antioxidant, anticancer, and antihyperglycemic activities. ${ }^{13,20}$

Currently, synthetic drugs are available for $\alpha$-amylase and $\alpha$-glucosidase inhibition and treatment for obesity, but the associated undesirable side effects such as bloating, abdominal discomfort, flatulence, and emesis, insomnia, myocardial infarction, and constipation have rendered them less attractive as therapeutic agents. ${ }^{21}$ A natural remedy that will be effective, inexpensive, and relatively safe is desirable.

To overcome these short-comings combined with the purported therapeutic effects of the mushroom in traditional medicine, the investigation became imperative. Hence, this study sought to assess antidiabetic, anti-obesity, and cytotoxicity potentials of $L$. squarrosulus as well as identify the mushroom using molecular techniques.

\section{MATERIALS AND METHODS}

\section{Reagents and chemicals}

Sodium hydroxide $(\mathrm{NaOH})$ solution $(2 \mathrm{M}), 1 \% \mathrm{w} / \mathrm{v}$ starch, 3, 5-dinitrosalicylic acid (DNSA), potassium sodium tartrate tetrahydrate $\left(\mathrm{C}_{4} \mathrm{H}_{12} \mathrm{KNaO}_{10}\right), 3 \%$ methanol, acarbose, phosphate buffer (20 mM, pH 6.9), DNSA solution ( $96 \mathrm{mM})$, maltose standard solution $0.2 \%(\mathrm{w} / \mathrm{v}), \alpha$-amylase (Aspergillus niger) sodium bicarbonate $\left(\mathrm{Na}_{2} \mathrm{CO}_{3}\right)$, p-nitro phenyl glucopyranoside (pNPG), $p$-nitrophenol, $\alpha$-glucosidase enzyme (Saccharomyces cerevisiae), orlistat, porcine pancreatic lipase enzyme, p-nitrophenyl butyrate ( $\mathrm{pNPB}$ ), dimethyl formamide, sodium chloride $(\mathrm{NaCl})$, ethanol, isolation buffer (Tris-EDTA), RNAse, polyvinylpyrrolidone, ITS1 and ITS4 primers, Taq DNA polymerase, Taq buffer, DNA template, sterile water, dNTPsmix and ethidium-stained agarose gel. All other chemicals and reagents used were of quality analytical grade and procured from commercially available sources.

\section{Mushroom sample collection and morphological identification}

The mushroom sample collection was carried out on the basis of the reported morphological features and characteristics of the mushroom ( $L$. squarrosulus) as described in mycological treaties. 9,10,22,23 The fruiting bodies of the mushroom were harvested from the University of Ibadan (Figure 1).

Molecular identification of a mushroom sample (L. squarrosulus) Extraction of the genomic DNA

The total DNA of the genome was extracted from the fruiting body of the mushroom using a plant/fungi DNA isolation kit (Norgen Biotek Corporation, Thorold, ON, Canada) strictly following the manufacturer's instructions for use. The DNA after extraction was then stored at $-20^{\circ} \mathrm{C}$ until required.

\section{Polymerase chain reaction (PCR) amplification of the genomic} DNA

Amplification of the extracted genomic DNA of the mushroom sample was performed by PCR using ITS1 (5'-TCCGTAGGTGAACCTGCGG-3') and ITS4 (5'-TCCTCCGCTTA TTGATATGC-3') primers. The reaction involved the use of Taq polymerase "Ready to Go" mixture (Pharmacia, Sweden), the primers and DNA template solution. A GenAmp PCR System 2400, Perkin-Elmer, USA was used to achieve 30 cycles of denaturation at $95^{\circ} \mathrm{C}$ for 30 seconds; primer hybridization/ annealing at $50^{\circ} \mathrm{C}$ for $1 \mathrm{~min}$; and primer extension at $72^{\circ} \mathrm{C}$ for

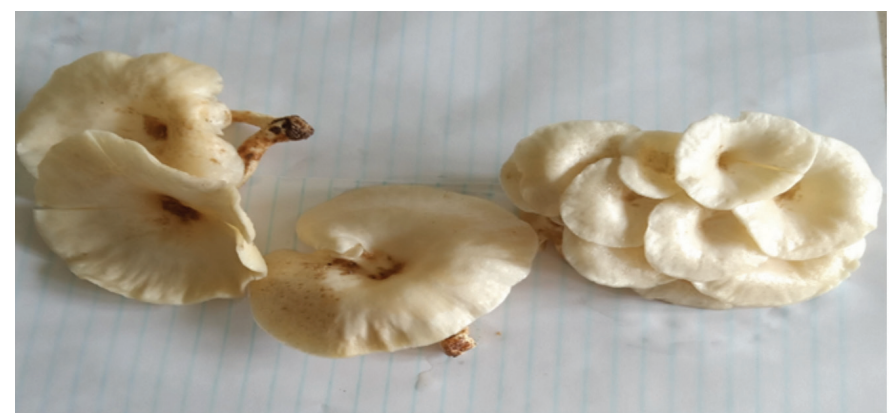

Figure 1. Harvested fruiting bodies of Lentinus squarrosulus Mont. 
another $1 \mathrm{~min}$. The products after amplification were subjected to gel purification and electrophoresis on ethidium-stained agarose gel $(0.7 \%)$. The products after that were directly sequenced and aligned using CLUSTAL W. ${ }^{24}$ The data obtained from the aligned sequences were used to plot a dendrogram tree using Molecular Evolutionary Genetic Analysis 4 software.

\section{Extraction of L. squarrosulus samples}

The collected mushrooms were freeze-dried and ground to coarse powder with the use of an electric blender. The powdered mushroom (200 g) was weighed and macerated in chloroform/methanol $(1: 1)$ at $70^{\circ} \mathrm{C}$ for $24 \mathrm{~h}$ in a sonicator. It was then filtered, and the filtrate was collected and concentrated to obtain the chloroform/methanol extract. The residue was dried and macerated in distilled water at $70^{\circ} \mathrm{C}$ for $24 \mathrm{~h}$ in a sonicator. The extract from the residue was filtered and lyophilized to obtain the aqueous extract. ${ }^{25,26}$ The weights of the chloroform/ methanol and aqueous extracts were recorded and the different percentage yields (\%) calculated.

\section{In vitro antidiabetic activity}

Evaluation of $\alpha$-amylase inhibitory activity of $L$. squarrosulus extracts

A reported method ${ }^{25}$ was used to determine the inhibition of $\alpha$-amylase activity of the chloroform/methanol and aqueous extracts of $L$. squarrosulus. Five graded concentrations of the extracts and acarbose (104.19-1667 $\mu \mathrm{g} / \mathrm{mL}$ ) were obtained through two-fold serial dilution in phosphate buffer $(20 \mathrm{mM}, \mathrm{pH}$ 6.9). Five hundred microliters $(500 \mu \mathrm{L})$ of the extracts/acarbose were dispensed into well-labeled test tubes, and $500 \mu \mathrm{L}$ of 2 units of $\alpha$-amylase solution was added. The resulting mixture was pre-incubated for $15 \mathrm{~min}$ at a temperature of $35^{\circ} \mathrm{C}$ followed by the addition of $500 \mu \mathrm{L}$ starch solution (1\%) to initiate the reaction. The reaction mixture was further incubated for $5 \mathrm{~min}$ at a temperature of $25^{\circ} \mathrm{C}$. Finally, $500 \mu \mathrm{L}$ of the colour reagent (96 mM DNSA and $5.31 \mathrm{M}$ sodium potassium tartrate in $2 \mathrm{M}$ $\mathrm{NaOH}$ ) was added to terminate the reaction and tubes were incubated inside the water bath at $80^{\circ} \mathrm{C}$ for $15 \mathrm{~min}$. The test tubes were removed and made to cool on ice; thereafter 4.5 $\mathrm{mL}$ of distilled water was added to dilute the reaction mixture. Two hundred microliters $(200 \mu \mathrm{L})$ each of the content in the test tubes were measured into a 96 well microtiter plate and the absorbance read at $540 \mathrm{~nm}$. The concentration of maltose formed was extrapolated from a maltose standard curve. Positive control (containing serially diluted acarbose) and negative control tubes (phosphate buffer) were also included.

\section{Evaluation of $\alpha$-glucosidase inhibitiory activity of $L$. squarrosulus extracts}

A previously reported method was used. ${ }^{25}$ The mushroom extracts and acarbose were prepared in phosphate buffer $(\mathrm{pH}$ 6.9). Five graded concentrations of the mushroom extracts and acarbose (78.13-1250 $\mu \mathrm{g} / \mathrm{mL}$ ) were determined by a twofold serial dilution in test tubes. One hundred $(100 \mu \mathrm{L})$ of $\alpha$-glucosidase enzyme ( $1 \mathrm{U} / \mathrm{mL})$ was pre-incubated with $50 \mu \mathrm{L}$ of the varying concentrations of the mushroom extracts for 10 min at room temperature. Then, the reaction was started by addition of $50 \mu \mathrm{L}$ of $3 \mathrm{mM}$ pNPG. The reaction mixture was brought to a stop by the addition of $2.5 \mathrm{~mL}$ of $0.1-\mathrm{M} \mathrm{Na}_{2} \mathrm{CO}_{3}$ solution after incubation at room temperature for $20 \mathrm{~min}$. $200 \mu \mathrm{L}$ each of the content in the test tubes were dispensed into a 96 well microtiter plate and the enzymatic activity of $\alpha$-glucosidase was after that determined by measuring the amount of the yellow $p$-nitrophenol released from the pNPG at $405 \mathrm{~nm}$ on the SPECTRAmax Gemini XS microplate reader. Positive control (containing serially diluted, acarbose) and negative control tubes (phosphate buffer) were also included.

\section{In vitro anti-obesity activity}

\section{Evaluation of anti-lipase activity of $L$. squarrosulus extracts}

Pancreatic lipase inhibition activity of the mushroom extracts was determined using pNPB as the substrate. The effect of the mushroom extracts on lipase activity was determined using a modified method described. ${ }^{27}$ The mushroom extracts and orlistat were prepared in phosphate buffer $(\mathrm{pH}$ 6.9). Two-fold serial dilution in test tubes were used to obtain five graded concentrations of the mushroom extracts and orlistat (78.13$1667 \mu \mathrm{g} / \mathrm{mL})$. The mushroom extracts and orlistat $(50 \mu \mathrm{L})$ were then, pre-incubated with $50 \mu \mathrm{L}$ of pancreatic lipase for $1 \mathrm{~h}$ in the reaction buffer at room temperature. pNPB $(1 \mu \mathrm{L})$ was added to initiate the reaction followed by further incubation of the reaction mixture for $5 \mathrm{~min}$ at the room temperature $\left(29^{\circ} \mathrm{C}\right)$. The amount of $p$-nitrophenol released in the mixture was estimated at 405 $\mathrm{nm}$ using a ultraviolet-visible (UV-Vis) spectrophotometer (SPECTRAmax Gemini XS, Molecular Devices, USA). Positive control (containing serially diluted orlistat) and negative control tubes (phosphate buffer) were also included.

\section{Cytotoxicity assessment}

The cytotoxicity assessment of $L$. squarrosulus extracts was carried out using the brine shrimp lethality assay. The eggs of Artemia salina (brine shrimp) were obtained from an aquarium shop, UK. The brine shrimp eggs were hatched in natural seawater (from Bar Beach, Lagos) contained in a small reservoir tank, under adequate illumination for $48 \mathrm{~h}$. The hatched nauplii (larvae) were attracted to the illuminated side of the tank and collected with a pasteur pipette. Ten of the brine shrimps (nauplii) were transferred into each extract at selected varying concentrations (5 dilutions, 1.6-5.0 $\mu \mathrm{g} / \mathrm{mL}$ ) in tubes. Cyclophosphamide was used as the positive control. After $24 \mathrm{~h}$, the number of surviving naupliis were counted. The percentage mortality of each concentration and $\mathrm{LC}_{50}$ were calculated and compared with the control. Data were carried out in triplicate. Crude extracts were considered toxic, when their LC $_{50}$ values were less than $100 \mu \mathrm{g} / \mathrm{mL} .^{28}$

\section{Phytochemical composition of $L$. squarrosulus extracts}

\section{Determination of total phenolic content (TPC)}

TPC of the chloroform/methanol and aqueous extracts of L. squarrosulus was assessed using the Folin-Ciocalteu's reagent using a previously reported method. ${ }^{29}$ Briefly, $0.1 \mathrm{~mL}$ of mushroom extract was mixed with $0.1 \mathrm{~mL}$ of Folin-Ciocalteu's reagent $(1: 1, v / v)$ and incubated for $5 \mathrm{~min}$. $1 \mathrm{~mL}$ of $7 \%$ sodium carbonate $\left(\mathrm{Na}_{2} \mathrm{CO}_{3}\right)$ solution was added to the mixture and distilled water was used to make up the volume of the mixture 
to $2.5 \mathrm{~mL}$. This was mixed thoroughly and kept in the dark for $90 \mathrm{~min}$ at room temperature. Absorbance was measured using a UV-Vis spectrophotometer at $750 \mathrm{~nm}$ against the reagent blank. TPC was expressed as gallic acid equivalent (GAE)/g of dry matter based on the standard curve.

\section{Determination of total flavonoid content (TFC)}

TFC of the mushroom extracts was determined using the aluminum chloride colorimetric method. ${ }^{30}$ The mushroom extract solution, $0.3 \mathrm{~mL}$ of $1 \mathrm{mg} / \mathrm{mL}$, was added to a mixture containing $3.4 \mathrm{~mL}$ of $30 \%$ methanol, $0.15 \mathrm{~mL}$ of $0.3 \mathrm{M}$ sodium nitrite $\left(\mathrm{NaNO}_{2}\right)$, and $0.15 \mathrm{~mL}$ of $0.3 \mathrm{M}$ aluminum chloride $\left(\mathrm{AlCl}_{3} \cdot 6 \mathrm{H}_{2} \mathrm{O}\right)$. The resulting mixture was incubated for $5 \mathrm{~min}$ at room temperature. Then, $1 \mathrm{~mL}$ of $1 \mathrm{M} \mathrm{NaOH}$ was added to the mixture. The absorbance of the reaction mixture was measured against the blank at $506 \mathrm{~nm}$ using a UV-Vis spectrometer. TFC, expressed as mg rutin equivalent (RE)/g of the dry matter, was calculated from the calibration curve.

\section{Statistical analysis}

$I_{50} / L C_{50}$ values are expressed as mean \pm standard error of mean of the three independent values. The values were compared using the Mann-Whitney $U$ test. $p$ values of $<0.05$ were considered a statistically significant difference.

\section{RESULTS}

Molecular identification of L. squarrosulus

The internal transcribed spacer (ITS) region sequence of the rDNA was used to identify the mushroom. The BLAST analytic result from Genbank revealed that the ITS sequence of the mushroom sample matched that of $L$. squarrosulus. with a unique accession number (KT120043.1). The dendrogram tree for L. squarrosulus is shown in Figure 2.

Extract yield of L. squarrosulus

The percentage yields of $\mathrm{CME}$ and $\mathrm{AE}$ of $L$. squarrosulus mushroom were 3.72 and $9.10 \%$, respectively (Table 1).

\section{Phytochemical analysis of L. squarrosulus extracts}

TPC and TFC

The results of the TPC and TFC of the CME and AE of $L$. squarrosulus are presented in Table 1. From the table, the CME (239.92 $\pm 0.65 \mathrm{mg} \mathrm{GAE} / \mathrm{g}$ sample) showed higher TPC than the $\mathrm{AE}$ (220.75 $\pm 0.34 \mathrm{mg} \mathrm{GAE} / \mathrm{g}$ sample). Similarly, TFC of $\mathrm{AE}$ (217.43 $\pm 0.85 \mathrm{mg} \mathrm{RE} / \mathrm{g}$ sample) was less than that of $\mathrm{CME}$ (348.86 $\pm 0.32 \mathrm{mg} \mathrm{RE} / \mathrm{g}$ sample). However, both extracts of $L$. squarrosulus possessed high TPC and TFC.

Inhibition of $\alpha$-amylase, $\alpha$-glucosidase and lipase activities of L. squarrosulus

Both extracts (CME and AE) of $L$. squarrosulus exhibited very low $\alpha$-amylase inhibitory activity at the tested concentrations with $I C_{50}$ values of $>1670 \mu \mathrm{g} / \mathrm{mL}$ compared to that of the standard, acarbose with an $\mathrm{IC}_{50}$ value of $726.49 \pm 1.66 \mu \mathrm{g} / \mathrm{mL}$ (Table 2). The CME of $L$. squarrosulus showed better inhibitory activity with an $\mathrm{IC}_{50}$ value of $451.13 \pm 2.14 \mu \mathrm{g} / \mathrm{mL}$ than the $\mathrm{AE}$ $\left(\mathrm{IC}_{50}>1250 \mu \mathrm{g} / \mathrm{mL}\right.$ ) against $\alpha$-glucosidase (Table 2). Although, it is not as active as acarbose with an $\mathrm{IC}_{50}$ value of $235.51 \pm 1.34$ $\mu \mathrm{g} / \mathrm{mL}$ against $\alpha$-glucosidase (Table 2). Furthermore, CME and $\mathrm{AE}$ exhibited lipase inhibitory activity with $\mathrm{IC}_{50}$ values of $28.11 \pm$ 1.37 and $22.28 \pm 0.65 \mu \mathrm{g} / \mathrm{mL}$ respectively. However, the orlistat had the best lipase inhibitor activity $\left(\mathrm{IC}_{50}: 2.28 \pm 0.34 \mu \mathrm{g} / \mathrm{mL}\right)$.

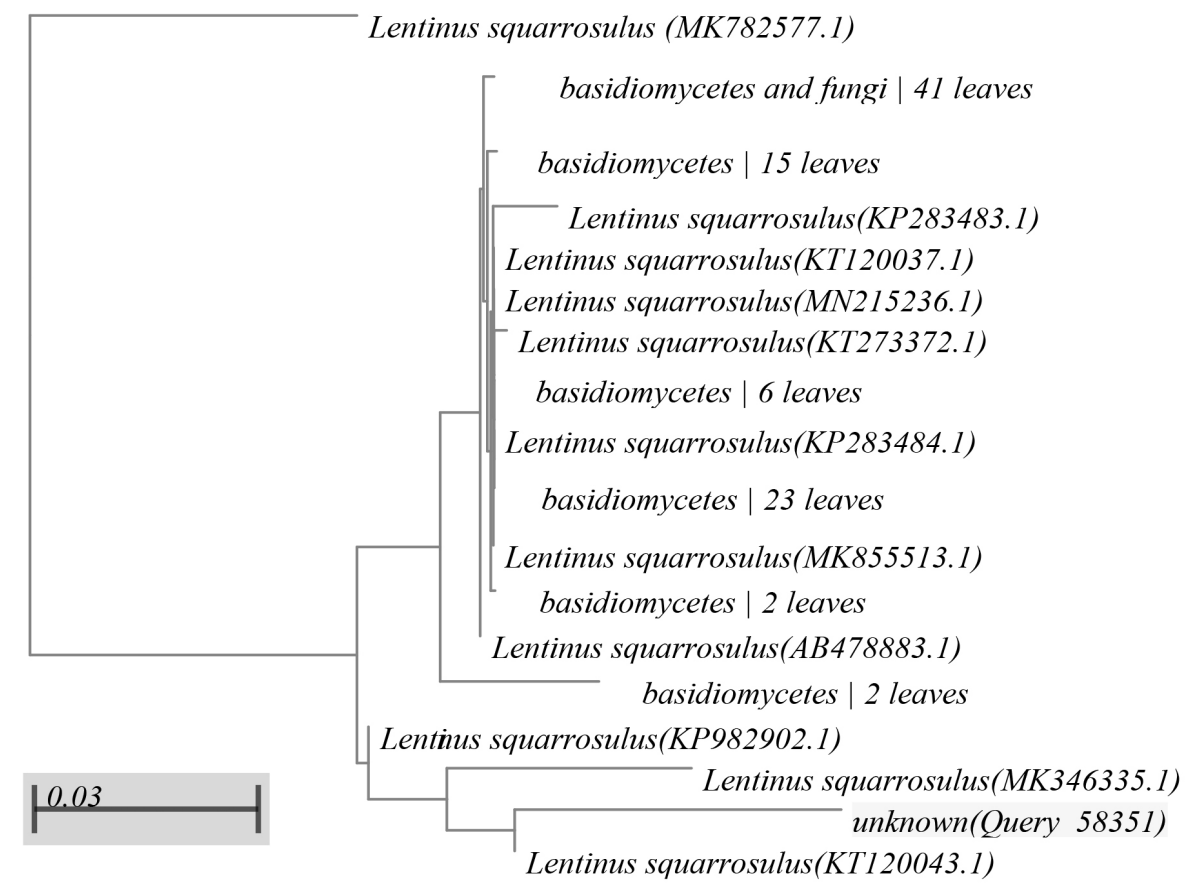

Figure 2. Dendrogram tree of Lentinus squarrosulus Mont. from phylogenetic analysis 
Table 1. Percentage yield, total phenolic content and total flavonoid content of Lentinus squarrosulus extracts

\begin{tabular}{llll} 
The extracts & Percentage yield (\%) & TPC (GAE/g sample) & TFC (mg RE/g sample) \\
\hline CME & 3.72 & $239.92 \pm 0.65$ & $348.86 \pm 0.32$ \\
\hline AE & 9.10 & $220.75 \pm 0.34$ & $217.43 \pm 0.85$ \\
\hline
\end{tabular}

TPC: Total phenolic content, TFC: Total flavonoid content, GAE: Gallic acid equivalent, RE: Rutin equivalent, CME: Chloroform/methanol extract, AE: Aqueous extract

Table 2. Cytotoxicity assessment, $\alpha$-amylase, $\alpha$-glucosidase, and pancreatic lipase inhibitory activities of Lentinus squarrosulus extracts

$\mathrm{IC}_{50} / \mathrm{LC}_{50}$ (mean $\left.\pm \mathrm{SEM}\right) \mu \mathrm{g} / \mathrm{mL}$ The extracts

\begin{tabular}{|c|c|c|c|}
\hline \multirow[b]{2}{*}{ In vitro assays } & \multicolumn{2}{|l|}{ The extracts } & \multirow{2}{*}{ Standard drugs } \\
\hline & CME & $\mathrm{AE}$ & \\
\hline$\alpha$-Amylase inhibition & $>1670$ & $>1670$ & $\star 726.49 \pm 1.66$ \\
\hline$\alpha$-Glucosidase inhibition & $451.13 \pm 2.14$ & $>1250$ & *235.51 \pm 1.34 \\
\hline Pancreatic lipase inhibition & $28.11 \pm 1.37$ & $22.28 \pm 0.65$ & $\# 2.28 \pm 0.34$ \\
\hline Cytotoxicity assessment & $257.10 \pm 1.33$ & $251.10 \pm 3.59$ & $+15.19 \pm 2.00$ \\
\hline
\end{tabular}

*Acarbose, ${ }^{\text {OOrlistat, }}{ }^{+}$Cyclophosphamide, SEM: standard error of mean, CME: Chloroform/methanol extract, AE: Aqueous extract

\section{Cytotoxicity assessment}

The result of the cytotoxicity assessment using brine shrimp lethality assay revealed that the CME and $\mathrm{AE}$ of $L$. squarrosulus had $\mathrm{LC}_{50}$ of $257.1 \pm 1.33 \mu \mathrm{g} / \mathrm{mL}$ and $251.1 \pm 3.59 \mu \mathrm{g} / \mathrm{mL}$ respectively, while cyclophosphamide had $\mathrm{LC}_{50}$ value of $15.19 \pm 2.00 \mu \mathrm{g} / \mathrm{mL}$.

\section{DISCUSSION}

To harness the numerous potentials that an organism offers, accurate and reliable taxonomy of such an organism is critical to confirm the biological species for various prospective usages. Molecular techniques, which employ the use of DNA barcoding using the ITS region sequencing eliminate the challenge of irregular morphology and possible indiscrimination among macrofungal species, which are often associated and remain a setback with morphological taxonomy. Molecular technique was used to identify $L$. squarrosulus in this study. ${ }^{31}$ The ITS rDNA region sequence as a proposition is considered as one of the most essential tools for identifying fungal species that are isolated from environmental and biological sources. ${ }^{32}$ This study revealed that the ITS sequences obtained for the mushroom sample compared to those in the database using NCBI-BLAST displayed significant sequences similar to the query sequences used to identify the organism with a high percentage similarity. Hence, the BLAST result identified the mushroom sample as L. squarrosulus, with a phylogenetic tree generated to further reveal and confirm the identity of the mushroom species.

In this study, it was observed that the extraction yield of the mushroom in aqueous water is higher than that of the chloroform/methanol. Water or an aqueous solution is more polar than chloroform/methanol, suggesting that the extraction yield increases with an increase in polarity. Similar findings that support the result of this study have been reported. ${ }^{23}$ Thus, the extraction yield may depend on one or more of the solvents with different polarities, the time of extraction, temperature, $\mathrm{pH}$, and composition of the sample.

Edible and medicinal mushrooms hold a definite promise as functional food and nutritional supplements to manage DM and obesity because of their rich bioactive components. ${ }^{33,34}$ These natural active substances or their primary metabolites consumed in traditional medicine or as nutraceuticals contain antioxidants, fibers, and other phytochemicals that favorably demonstrate both anti-obesity and antidiabetic activities through the modulation and regulation of diverse cellular and physiological pathways. These effects include appetite regulation, modulation of lipid absorption and metabolism, enhancement of insulin sensitivity, thermogenesis, and changes in the gut microbiota. ${ }^{34}$

Disease conditions such as obesity, hyperlipidemia, and T2DM are likely to occur, when there is an imbalance between energy intake and energy expenditure. ${ }^{35,36}$ To treat these complications and obesity, the enzymatic inhibition of pancreatic lipase is a very essential path. Dietary fats consisting of triglycerides are hydrolyzed to release fatty acids and glycerol, which are absorbed by the mucosa of the small intestine. In response to food intake, lipase is therefore secreted by pancreas into the small intestine to catalyze the hydrolysis step. The drug orlistat, which is used to treat obesity, inhibits the activity of human pancreatic lipase by forming a bond that is covalently linked with the enzyme at its active site. ${ }^{34,36}$ Many of the phytochemically active components, such as flavonoids, saponins, polyphenols, and caffeine have been shown to inhibit pancreatic lipase activity in vitro and are comparable to orlistat. ${ }^{36}$ In this study, both extracts of $L$. squarrosulus inhibited pancreatic lipase enzyme activity. Mushrooms have been well documented to have antiobesity effects through various possible mechanisms. A study evidenced that Lentinus edodes and Cordyceps militaris reduced triglyceride, total cholesterol, plasma glucose, and hypertension 
in diabetic rats. ${ }^{37}$ Lentinus strigosus another species of Lentinus, was reported to possess anti-obesity activity by affecting the food intake and locomotion of Caenorhabditis elegans. ${ }^{38}$ In this study, L. squarrosulus exhibited anti-obesity effects through inhibition of pancreatic lipase activity. Pleurotus sajor-caju and Adiantum capillus-veneris have also shown similar anti-obesity activity through the same mechanism in addition to lowering total cholesterol, triglycerides, and atherogenic index. 5,39 These observed activities are attributed to the presence of bioactive components such as saponins, flavonoids, and polyphenols.

$D M$ is a consequence of unequilibrated insulin production and/or insensitivity to the effect of this hormone in signal transduction of cellular receptors. Most of the T2DM complications are due to hyperglycemia as their main cause. ${ }^{4}$ One of the effective strategies for T2DM management is the inhibition of complex polysaccharide hydrolysis by pancreatic $\alpha$-amylase and absorption limitation of glucose by inhibiting intestinal $\alpha$-glucosidase. Mushrooms have antidiabetic properties with different mechanisms of action. $\beta$-Glucans and their enzymatically hydrolyzed oligosaccharides from the mushroom Agaricus brasiliensis show antiarteriosclerotic and antihyperglycemic activities, indicating antidiabetic activity in diabetic rats, which corroborates with enhanced insulin secretion from pancreatic islets and proliferation of islets in diabetic or normal rats. ${ }^{36}$ The results of our study revealed that the chloroform/methanol extract of $L$. squarrosulus had the highest $\alpha$-glucosidase inhibitory activity, while the extracts of $L$. squarrosulus did not show any inhibitory effect on $\alpha$-amylase at the concentrations tested. Stojkovic et al. ${ }^{37}$ in 2017 reported antidiabetic activity of methanol extract of Morchella conica as another mushroom species that did not inhibit $\alpha$-amylase activity; but had inhibitory potential on $\alpha$-glucosidase activity. Moreover, a previous study revealed terpenoids as inhibitors of $\alpha$-glucosidase. ${ }^{39}$ L. squarrosulus contains bioactive components such as terpenoids, saponins, and polyphenols amongst others. ${ }^{40}$ Hence, the antidiabetic activity of $L$. squarrosulus through inhibition of $\alpha$-glucosidase activity leading to delayed process of glucose uptake may be attributable to the presence of terpenoids and other bioactive components.

The need to know the toxic potential of edible and medicinal mushrooms is paramount for their safe consumption and usage. The brine shrimp test is a rapid and simple bioassay for testing lethality of extracts as a means of ascertaining their cytotoxic properties. The test system has been proven to be convenient for monitoring the biological activities of products of natural origin. ${ }^{41}$ L. squarrosulus mushroom extracts appeared less toxic than cyclophosphamide, a standard toxic drug. Hence, it is relatively safe at the tested concentrations.

\section{CONCLUSION}

In conclusion, obesity and T2DM are however complex disease conditions, to prevent, treat, and manage these diseases and their complications, a holistic approach is required that involves a combination of factors such as regular exercise, diet modifications, and pharmacotherapy that requires further advancements. Mushrooms, due to their numerous bioactive components and reported therapeutic advantages, appear promising in the search for treating obesity and T2DM. Therefore, the outcome of this study indicates that the chloroform/methanol extract of $L$. squarrosulus mushroom, rich in polyphenols and flavonoids possess considerable $\alpha$-glucosidase and pancreatic lipase inhibitory activities and appears less toxic. Thus, it might be explored or combined with existing treatments to reduce the prevalence of diabetes and obesity, and their complications.

\section{ACKNOWLEDGMENTS}

The authors appreciate the technical assistance of Ms. Oluwayimika Olumide and Ogooluwa Odetoye.

\section{Ethics}

Ethics Committee Approval: Not applicable.

Informed Consent: Not applicable.

Peer-review: Externally peer-reviewed.

\section{Authorship Contributions}

Concept: O.O.A., Design: O.O.A., A.M.A., O.A., Data Collection or Processing: A.M.A., A.N., O.A., Analysis or Interpretation: O.O.A., P.U.E., A.N., T.A.O., Literature Search: A.M.A., O.A., P.U.E., Writing: O.O.A., A.M.A., P.U.E., T.A.O.

Conflict of Interest: No conflict of interest was declared by the authors.

Financial Disclosure: The authors declared that this study received no financial support.

\section{REFERENCES}

1. Sami W, Ansari T, Butt NS, Hamid MRA. Effect of diet on type 2 diabetes mellitus: a review. Int J Health Sci (Qassim). 2017;11:65-71.

2. WHO. World Health Organization: Prevalence of obesity and overweight fact sheet and reports. Access date: 03.10.2021. Available from: who.int/ news-room/fact-sheets/detail/obesity-and-overweight

3. Peng X, Zhang G, Liao Y, Gong D. Inhibitory kinetics and mechanism of kaempferol on $\alpha$-glucosidase. Food Chem. 2016;190:207-215.

4. Furukawa S, Fujita T, Shimabukuro M, Iwaki M, Yamada Y, Nakajima Y, Nakayama O, Makishima M, Matsuda M, Shimomura I. Increased oxidative stress in obesity and its impact on metabolic syndrome. J Clin Invest. 2004;114:1752-1761.

5. Kanagasabapathy G, Malek SN, Mahmood AA, Chua KH, Vikineswary S, Kuppusamy UR. Beta-glucan-rich extract from Pleurotus sajor-caju (Fr.) Singer prevents obesity and oxidative stress in C57BL/6J mice fed on a high-fat diet. Evid Based Complement Alternat Med. 2013;2013:185259.

6. You $Q$, Chen F, Wang $X$, Jiang $Y$, Lin S. Anti-diabetic activities of phenolic compounds in muscadine against alpha-glucosidase and pancreatic lipase. LWT-Food Sci Technol. 2012;46:164-168.

7. Yang MH, Chin YW, Yoon KD, Kim J. Phenolic compounds with pancreatic lipase inhibitory activity from Korean yam (Dioscorea opposita). J Enzyme Inhib Med Chem. 2014;29:1-6.

8. Inthongkaew P, Chatsumpun N, Supasuteekul C, Kitisripanya T, Putalun W, Likhitwitayawuid K, Sritularak B. $\alpha$-Glucosidase and pancreatic lipase inhibitory activities and glucose uptake stimulatory effect of phenolic compounds from Dendrobium formosum. Rev Bras Farmacogn. 2017;27:480-487. 
9. Njouonkou AL, Mossebo DC, Akoa A. The genera Lentinus and Panus in the Dja biosphere reserve and its periphery in Cameroon. Kew Bull. 2013:68:517-521.

10. Mortimer P, Xu J, Karunarathna S, Hyde KD. Mushrooms for trees and people: a field guide to useful mushrooms of the Mekong region ( $1^{\text {st }}$ ed). Kunming, China: ICRAF. 2014;125.

11. Akpaja EO, Isikhuemhen OS, Okhuoya JA. Ethnomycology and usage of edible and medicinal mushrooms among the Igbo people of Nigeria. Int $\mathrm{J}$ Med Mushrooms. 2003:5.

12. Adebiyi AO, Yakubu HO. A survey of mushrooms in two local government areas of Ekiti state, Nigeria. DJAR. 2016;3:13-16.

13. Mhd Omar NA, Abdullah N, Kuppusamy UR, Abdulla MA, Sabaratnam V. Nutritional composition, antioxidant activities and antiulcer potential of Lentinus squarrosulus (Mont.) mycelia extract. Evid Based Complement Alternat Med. 2011;2011:539356.

14. Okigbo RN, Nwatu CM. Ethnostudy and usage of edible and medicinal mushrooms in some parts of Anambra state, Nigeria. Nat Resour. 2015;6:79-84.

15. Oyetayo OV. Medicinal uses of mushrooms in Nigeria: towards full and sustainable exploitation. Afr J Tradit Complement Altern Med. 2011;8:267-274.

16. Mhd Omar NA, Abdullah S, Abdullah N, Kuppusamy UR, Abdulla MA, Sabaratnam V. Lentinus squarrosulus (Mont.) mycelium enhanced antioxidant status in rat model. Drug Des Devel Ther. 2015;9:5957-5964.

17. Obodai M, Ferreira IC, Fernandes A, Barros L, Mensah DL, Dzomeku M, Urben AF, Prempeh J, Takli RK. Evaluation of the chemical and antioxidant properties of wild and cultivated mushrooms of Ghana. Molecules. 2014;19:19532-19548.

18. Borokini F, Lajide L, Olaleye T, Boligon A, Athayde M, Adesina I. Chemical profile and antimicrobial activities of two edible mushrooms (Termitomyces robustus and Lentinus squarrosulus). J Microbiol Biotechnol Food Sci. 2016;5:416-423.

19. Jonathan S, Olawuyi O, Oluranti O. Studies on immunomodulatory and prophylactic properties of some wild Nigerian mushrooms. Academia Arena. 2012;4:39-45.

20. Rungprom W. Antioxidant and antihyperglycemic activities of four edible Lentinus mushrooms. Curr J Appl Sci. 2018;18:75-82.

21. Kennett GA, Clifton PG. New approaches to the pharmacological treatment of obesity: can they break through the efficacy barrier? Pharmacol Biochem Behav. 2010;97:63-83.

22. Pegler DN. The genus Lentinus. Kew Bull Addit Ser. 1983;10:1-28.

23. Roy DR, Krishnappa M. Mycochemical profiling of Lentinus squarrosulus Mont., a wild edible macrofungi using GC-MS. Int J Pharm Sci Res. 2018;9:4349-4354.

24. Thompson JD, Gibson TJ, Plewniak F, Jeanmougin F, Higgins DG. The CLUSTAL_X windows interface: flexible strategies for multiple sequence alignment aided by quality analysis tools. Nucleic Acids Res. 1997;25:4876-4882.

25. Abiodun $\mathrm{OO}$, Tijani R, Ogbole O, Ajaiyeoba E. Antioxidant, alpha-amylase and alpha-glucosidase inhibitory activities of leaf and flower extracts and fractions of Phaulopsis falcisepala CB Clarke. Acta Pharm Sci. 2018;56:23-33.

26. Ugbogu EA, Akubugwo IE, Ude VC, Gilbert J, Ekeanyanwu B. Toxicological evaluation of phytochemical characterized aqueous extract of wild dried Lentinus squarrosulus (Mont.) mushroom in rats. Toxicol Res. 2019;35:181-190.

27. Kim YS, Lee YM, Kim H, Kim J, Jang DS, Kim JH, Kim JS. Anti-obesity effect of Morus bombycis root extract: anti-lipase activity and lipolytic effect. J Ethnopharmacol. 2010;130:621-624.

28. Fang XP, Rieser MJ, Gu ZM, Zhao GX, McLaughlin JJ. Annonanceous acetogenins: an updated review-appendices. Phytochem Anal. 1993;4:2748.

29. Kim DO, Chun OK, Kim YJ, Moon HY, Lee CY. Quantification of polyphenolics and their antioxidant capacity in fresh plums. J Agric Food Chem. 2003;51:6509-6515.

30. Chang CC, Yang MH, Wen HM, Chern JC. Estimation of total flavonoid content in propolis by two complementary colorimetric methods. J Food Drug Anal. 2002;10:3-15.

31. Appiah T, Agyare C, Luo Y. Molecular identification of some Ghanaian mushrooms using internal transcribed spacer regions. Mol Biol. 2017;6:191-199.

32. Anderson IC, Parkin PI. Detection of active soil fungi by RT-PCR amplification of precursor rRNA molecules. J Microbiol Methods. 2007;68:248-253.

33. Martel J, Ojcius DM, Chang CJ, Lin CS, Lu CC, Ko YF, Tseng SF, Lai $H C$, Young JD. Anti-obesogenic and antidiabetic effects of plants and mushrooms. Nat Rev Endocrinol. 2017;13:149-160.

34. Martins F, Noso TM, Porto VB, Curiel A, Gambero A, Bastos DH, Ribeiro

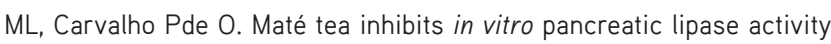
and has hypolipidemic effect on high-fat diet-induced obese mice. Obesity (Silver Spring). 2010;18:42-47.

35. Wang L, Xu N, Zhang J, Zhao H, Lin L, Jia S, Jia L. Antihyperlipidemic and hepatoprotective activities of residue polysaccharide from Cordyceps militaris SU-12. Carbohydr Polym. 2015;131:355-362.

36. Kim YW, Kim KH, Choi HJ, Lee DS. Anti-diabetic activity of beta-glucans and their enzymatically hydrolyzed oligosaccharides from Agaricus blazei. Biotechnol Lett. 2005;27:483-487.

37. Stojkovic D, Smiljkovic M, Ciric A, Glamoclija J, Van Griensven L, Ferreira ICFR, Sokovic M. An insight into antidiabetic propertiess of six medicinal and edible mushrooms: inhibition of $\alpha$-amylase and $\alpha$-glucosidase linked to type-2 diabetes. S Afr J Bot. 2019;120:100-103.

38. Babac, BD, Dulay, MRR, Calpito, RAS, Domingo, MA, Macamos, MGM., Mangabat AR, Zoberiaga, NZL. In-vitro activity of ethanolic extract of Lentinus strigosus mycelia in N2 wild strain Caenorhabditis elegans an animal model for obesity and its chemical composition. J Appl Biol Biotechnol. 2021;9:41-46.

39. Ying YM, Zhang LY, Zhang X, Bai HB, Liang DE, Ma LF, Shan WG, Zhan ZJ. Terpenoids with alpha-glucosidase inhibitory activity from the submerged culture of Inonotus obliquus. Phytochemistry. 2014;108:171176.

40. Attarat, J, Thamisak R. Anticancer PSP and phenolic compounds in Lentinus squarrosulus and Lentinus polychorous. Available from: https://www.thaiscience.info/Article\%20for\%20ThaiScience/ Article/2/10031486.pdf

41. Chanda S, Baravalia Y. Brine shrimp cytotoxicity of Caesalpinia pulcherrima aerial parts, antimicrobial activity and characterisation of isolated active fractions. Nat Prod Res. 2011;25:1955-1964. 